\title{
Research of Impacts on the Eco-Environment of Hydraulic and Hydropower Construction
}

\author{
Jie Chen ${ }^{1, a}$ \\ ${ }^{1}$ Sichuan Electric Vocational and Technical College, Chengdu, Sichuan, 610072, \\ ${ }^{a}$ email
}

Keywords: Eco-Environment, Hydraulic and Hydropower Construction, Impacts Study

\begin{abstract}
With the social and economic development in today's technology, the natural eco-environment is disturbed by destruction, and with the improvement of people's living standards, the quality of the environment is poured more and more attention, so for Hydraulic and Hydropower Engineering Eco-environment impact assessment is a work of great significance. Hydraulic and Hydropower project construction and operation will have an impact on the environment, involving many factors which affect the natural environment, eco-environment and social environment at the time of Hydraulic and Hydropower Engineering eco-environment impact assessment, these factors must be considered. Hence, Hydraulic and Hydropower Project Ecological and Environmental Impact Assessment is a complex project, the establishment of a complete and accurate evaluation system is an important prerequisite to complete the evaluation work.
\end{abstract}

\section{Introduction}

Eco-environment impact assessment is ecological impact of human development and construction activities may lead to the analysis and forecasting, and proposed strategies and measures to reduce or improve the eco-environment. Eco-environmental impact assessment of the main target of all development projects, regional development and construction activities of organisms and their habitats. Ecological Analysis and protection measures focus on evaluation methods, quantitative and qualitative analysis combined with a comprehensive analysis and evaluation of the eco-environment. Purpose of the ecological impact of Hydraulic and Hydropower Project to assess the main objective is to correctly understand the impact of Hydraulic and Hydropower Project on Eco-environment and Its Dynamic Change causes and laws.

Development and construction of Hydraulic and Hydropower Engineering generating social and economic benefits are obvious, can effectively alleviate the country's energy shortage situation, improve traffic and protect people's lives and property; but at the same time, Hydraulic and Hydropower Engineering led directly or indirectly Eco series of negative environmental impacts, such as water pollution, deterioration of water quality, soil erosion, reservoir seepage, reservoir induced seismicity, habitat change, biodiversity decline, river continuity destruction, population health issues; awareness and systems comprehensive evaluation of positive or negative impact on eco-environment, help policy makers formulate more targeted remediation or mitigation measures to enhance the sustainability of Hydraulic and Hydropower development.

\section{Relationship between Hydraulic and Hydropower Construction and Eco-environment}

A close relationship between Hydraulic and Hydropower Engineering Construction and Eco-environment is described in this paper. From the general sense, Hydraulic and Hydropower Engineering in the realization of the huge economic and social benefits at the same time, the construction of the building and operation are also different degrees destroy the balance of the original eco-environment. Effect of Hydraulic and Hydropower Engineering including immigration, the impact of sediment and river, climate, hydrology, geology soil water influence,,,, and fish species of the impact on the landscape and heritage, as well as to human health impacts. Hydraulic and Hydropower Engineering Construction under the premise must maximize the protection of the eco-environment, otherwise it is difficult to ensure the long-term development of the cause of 
Hydraulic and Hydropower Engineering. With economic development and population growth, human demand for water is increasing in many rivers have built water conservancy projects to regulate the amount of water, development and utilization of water resources to meet the water supply, flood control, irrigation, power generation, shipping and other needs. Water conservancy projects in economic development, social progress and to play a significant role in promoting the same time, the eco-environment also has a positive effect. Water by adjusting the amount of water wet and dry, the rational allocation of water resources, prevention of drying up the river, mitigation of flood and drought disaster losses, resist the impact of floods on ecosystems, but also improve the ecological situation in arid and semi-arid areas, etc., give full play various functions of the river, and promote social and economic development.

Xiaolangdi Water Control Project as an example for analysis. Since October 1999 under Xiaolangdi Dam impoundment, through careful scheduling, scientific management, flood control, sedimentation reduction, water supply, irrigation, ecology, power generation has played a huge benefit. Meanwhile reasonable dispatch, and also protect the lower reaches of the Yellow River estuary ecological flow requirements, greatly improved the eco-environment in downstream of the Yellow River, the Yellow River Delta wetland area increased significantly.

After the reservoir, impounding dam, water flow rate due to the purification of polluted body is different, so you can produce both positive and negative impact on water quality. Reservoir water body generally slow flow, long residence time is conducive to the settlement of suspended solids, turbidity of the water body can chromaticity reduced. At the same time the library slow flow, frequent algae, $\mathrm{CO} 2$ and water calcium produced by respiration and magnesium ions combine to produce $\mathrm{CaCO} 3$ and $\mathrm{MgCO} 3$ and settle down, reducing the hardness of the water, reducing the increase may be due to the basic cause of increased water toxicity. After impoundment, reservoir flow velocity slowed, reducing the dispersal ability of water, the rate of gas exchange interface and contaminants, so reoxygenation diminished capacity, making the reservoir water purification capacity is weaker than the river. Meanwhile Reservoir flow velocity is slow, slow water replacement, improved transparency is conducive to photosynthesis of algae, under sufficient nitrogen and phosphorus nutrients, proper temperature and adequate lighting conditions, Tail prone to some libraries Bay water eutrophication.

After the completion of the reservoir, the flow rate slows, almost part of the waters became still water for phytoplankton growth provides a good environment. To slow down, after the suspended sediment, improve water clarity is conducive to photosynthesis phytoplankton. After a lot of farmland were flooded, nutrient salts and organic matter decomposition was dissolved in water, a large accumulation of nutrients in the reservoir area for the growth of phytoplankton provides a wealth of material conditions. After impoundment, cutting off the migration routes of migratory fish, resulting in degradation of biodiversity. Fish, especially migratory fish, aquatic plants, animals, microorganisms may be due to the migration routes blocked, feeding spawning grounds disappeared, the water temperature and flow rate changes and changes in habitats affected, or even die. For example, after the completion of the Xiaolangdi Reservoir water is relatively static, copper fish spawning greater impact; deep reservoir discharged water temperature decreases, the impact downstream fish growth and reproduction; discharged water, the impact downstream fish bait, thus Effect of fish yields.

Water generating significant benefits, but also have a negative impact on the social environment. In terms of human health, many diseases directly or indirectly related to the water environment, such as some water-mediated disease due to the expansion of the water and increased immigration will lead to the relocation of some of the epidemics and the like. After Reservoir inundation, the potential impact on heritage and landscape. Meanwhile, the construction of Hydraulic and Hydropower Engineering of migration, land use also exists to some extent. In population, less arable land of the conditions should minimize loss of submerged reservoir, and the reservoir area only when the high water flooded the land use appropriate measures to be taken. 


\section{Ecol-Environmental Impact Assessment Procedures and the Main Content}

The first step: collecting basic information, be careful research and analysis. Step Two: On the basis of basic information for research and analysis, to determine the factors that have an impact on the eco-environment, the establishment of eco-environmental impact evaluation system. The third step: refer to the relevant normative standards or methods of expert scoring index system factors quantized to have maneuverability. Step four: adaptive neural network fuzzy inference system evaluation model pumped storage hydropower station. Step five: evaluation using MATLAB software to solve the model, analysis model results.

Impact Assessment of Hydraulic and Hydropower Engineering eco-environment includes the natural environment, social environment and environmental aspects of the evaluation. It can be summed up in the following aspects: The impact on the natural environment, including water quality, water temperature, flow, geological environment, atmospheric environment and so on. The impact on the eco-environment, Including diversity, habitat change, water and soil affect the biological environment and so on.

\section{Eco-environment Protection}

To further improve the Hydraulic and Hydropower Engineering, Environmental Impact Evaluation System. Improvement of environmental impact assessment specifically Hydraulic and Hydropower project examination and approval procedures of environmental impact assessment and soil conservation programs in the pre-feasibility study report for approval, improve relevant laws and regulations. Take policy guidance, based on scientific analysis and evaluation, forecasting and comprehensive description of the major impact of Hydraulic and Hydropower Engineering possible eco-environment, scientific development of Hydraulic and Hydropower.

Establish and implement ecological compensation mechanism as soon as possible. According to who develop, who compensation, benefits, who compensation, who destroyed the principle of who recovered, the establishment of a stable, law-based compensation mechanism. On the basis of the environmental impact assessment on the forecast, by providing fish passage facilities, Restocking, habitat compensation measures to coordinate the construction and the relationship between the protection of aquatic organisms. Such as the adverse effects of development on the river for aquatic organisms, taking fish passages, such as the establishment of nature reserves at the same time, the use of compensatory measures of artificial reproduction and releasing, in order to curb the decline of biological resources.

Strengthen the environmental protection work in construction. Hydraulic and Hydropower Engineering in construction, strengthen environmental management, to carry out the construction zone air, noise, water (surface water, groundwater, waste water) monitoring, real-time control of construction of state of the environment.

\section{Ecological Indicators for Evaluating of the Environmental Impact}

Due to the different natural environment, eco-environment, social environment and affected by human factors, therefore, to establish a comprehensive energy accurately reflect the specific Hydraulic and comprehensive evaluation index system Hydropower Construction Project. Indicators for evaluating the general to go through the following steps:

Analysis of the main ecosystems within a particular project area, representative of the environmental characteristics of the project area ecological ecosystem called the main ecosystems. Status and trends of ecosystem analysis body, which is the first step in the establishment of evaluation index system is also an important step.

Target decomposition and leading factor in determining the target based on the logical relationship between the constituent elements of the objectives of the decomposition, according to the part to the whole, macro and micro, the principle of long-term and recent combination of the 
various systems analysis of mutual influence between the factors relations, influence, etc., to determine the dominant factor, the establishment of a comprehensive system of evaluation system. Dominant factor can be statistical information, expert scoring method, SPSS software and other methods to determine the dominant factor.

After the system is determined by analysis the final index system, initially developed evaluation system, should be further screened index system, revised and improved, in order to finalize the indicators.

\section{Conclusion}

The eco-environment is the sum of all external conditions affect humans and biological survival and development is the basis for sustained social and economic development. Modern Hydraulic and Hydropower Engineering Construction of Social Development plays an active role, resulting in huge economic, social and eco-environment benefit, but to a certain extent affect, changed natural ecosystems. With the accelerated pace of water conservancy, its impact on the environment is increasing water use, environmental problems caused by the construction of water conservancy projects has been attention. In the new era, to use the scientific concept of development and human harmony with nature the idea of Hydraulic and Hydropower handle the relationship between development and eco-environment under the premise of protecting the eco-environment of the positive development of Hydraulic and Hydropower Engineering, achieve Hydraulic and Hydropower Resources Development and Ecology win environmental protection.

\section{References}

[1] John T. Lee et al, 1999, The Role of GIS in landscape Assessment Using Land-use-based Criterta for an Area of the Chilton Hills Area of Outstanding Natural Beauty, Land Use Policy, 16, 23-32.

[2] Wynet Smith et al,1999, Exploring Methods for Rapid Assessment of woody Vegetatson in the Batemi valley, North-central Tanzania, Biodiversity and Conservation, 8, 447-470.

[3] Ileana Espejel et al, 1999, Land-use Planning for the Guadalupe valle, Baja California, Mexico, Landscape and Urban planning, 45, 219-232.

[4] Robin S.Reid et al, 2000, Land-use and Land-cover Dynamics in Response to changes in Climatic, Biological and socio-political Forest: the Case of southwestern Ethiopia, Landscape Ecology, 15, 339-355.

[5] Daniel T. Heggem et al, A Landscape Ecology Assessment of the tensas River Basin, Environmental Monitoring and Assessment, 2000(64), 41-54. 